\title{
HEALTH STATUS, PHYSICAL FITNESS, AND CARDIOVASCULAR RISK FACTORS IN A PHYSICALLY ACTIVE POPULATION IN PORTO ALEGRE, BRAZIL
}

\section{Alexandre Luis Ritter²}

\author{
abstract
}

Objectives: The purpose of this study is to investigate the health and estimate the cardiovascular disease risk of a physically active population in Porto Alegre, Brazil. Methods: The sample consisted of 592 elderly individuals from five units of Porto Alegre Municipal Sports, Recreation, and Leisure Center (SME-PMPA). Patient histories were obtained, and all the patients underwent anthropometric and functional evaluations. Results: The results demonstrated compatibility between self-reported diseases and regularly used medications. They also revealed a high prevalence of the use of proton-pump inhibitors. The participants were classified as irregularly active and active

1 I thank the Municipal Secretary for Sports, Recreation, and Leisure of Porto Alegre, José Edgar Meurer and the pedagogical management and teachers Lieselote Inês Schmidt and Ana Luisa Madruga de Rodrigues for their institutional support. I also thank teachers Ariádene Milani, Nilo Joel do Amaral Sena, Rejane Penna Rodrigues, Gilmar Tondin, Gillberto Gonçalves de Aguiar, Fábio Canto da Silva, Gualcira Batista Teixeira, Fernando Matos Dourado Neto, Jarbas Clemente Araújo, Beatriz Cafruni, Júlio Cesar Gonçalves, Fledge Rita, and Patricia Schneider Regina who worked hard to collect and systematize the data. Finally, I thank all the trainees who were involved in this research project.

2 Graduated in Physical Education. Doctor degree in Human Movement Sciences. Effective professor of the Municipality of Porto Alegre, linked to the Secretary of Sports, Recreation and Leisure. E-mail: alexandreluisritter@gmail.com. 
according to the IPAQ classification. The systolic blood pressure of $44.8 \%$ of the participants was optimal, and the diastolic blood pressure of $83.1 \%$ of the study group was normal. The lipid profiles, with the exception of high-density lipoprotein (HDL) cholesterol, of most of the participants were satisfactory. In the study group, 29\% of the participants had prediabetes according to their fasting blood glucose levels, and 6.9\% had diabetes. The anthropometric evaluations (body mass index [BMI] and waist to hip ratio [WHR]) revealed an increased prevalence of cardiovascular disease risk factors among the majority of the participants. According to the functional evaluations, the balance and range of motion of the majority of the elderly population were satisfactory or good. However, the performance of the participants was not as good in the strength tests. The Framingham score showed that $4 \%$ of the study group had a high risk of cardiovascular disease. Conclusion: These results are in accordance with the characteristics of the population. However, health indicators of a large number of the participants were inadequate, and new strategies are needed to improve these.

keywords

Lifestyle. Exercise. Heart Disease. Health Education.

\section{Introduction}

Cardiovascular diseases account for almost $30 \%$ of all deaths recorded in Brazil (BRASIL, 2011). In 2015, about 350,000 cardiovascular disease-related deaths were registered in Brazil, twice as many as neoplasms and 2.3 times as many as external causes (i.e., homicides and accidents) (SBC, 2016). In terms of costs, cardiovascular diseases affected about two million people in 2004 and incurred expenditure of approximately $\mathrm{R} \$ 31$ billion in treatments, surgical interventions, social security, and loss of productivity (AZAMBUJA et al., 2008). Therefore, cardiovascular diseases incur high costs, both emotional and economic and encompass a large portion of the population.

Cardiovascular diseases have multiple causes, including genetic (inherited factors) and lifestyle factors. Genetic factors are among those that cannot be modified. However, lifestyle factors can be modified. These include a poor diet, which can significantly increase the occurrence of cardiovascular diseases (FUNG et al., 2016). 
Regular physical exercise has been shown to decrease the chance of developing cardiovascular diseases. Pranava yoga decreased systemic blood pressure in young adults with prehypertension (JAIN, 2016). Similarly, strength training improved some health indicators, such as lipid profiles (WENZEL; UNGER, 2016). Decreased glycosylated hemoglobin and total cholesterol levels also reduced the risk of developing cardiovascular diseases (D'AGOSTINO et al., 2008).

The present study aimed to collect information on the general health of elderly individuals who undertook regular physical exercise at Porto Alegre Municipal Sports, Recreation, and Leisure Center (SME-PMPA).

\section{Methods}

This is a descriptive study trying to give a small picture of the health status of physically active elderly in Porto Alegre, Brazil. It assessed risk factors for cardiovascular disease, anthropometric measures, and functional evaluations for all men and women.

\subsection{Study population}

The study population consisted of elderly individuals enrolled in physical exercise programs in one of five SME-PMPA units: Ararigboia Park, Tamandaré Park, Edgar Graeff Square, Vila Elisabeth Community Center (CECOVE), and $1^{\circ}$ de Maio Community Center (CEPRIMA). To calculate the sample size, the results of a pilot study carried out in October 2015 were used. All the instruments and procedures were tested in this pilot study to evaluate their applicability. Based on the values found in this pilot study, low-density lipoprotein (LDL) cholesterol values $(\bar{x}=127.70)$ showed the highest standard deviation. Thus, considering a standard deviation of 33.55, a maximum error estimate of 5 points, and a significance level of $5 \%$, a minimum of 173 participants was required for the present study.

After disclosure of the evaluations and scheduling of the study, the nonprobability convenience sampling method was used for data collection. Individuals attending the SME-PMPA were invited to take part in the study. During this invitation period, informed consent forms were provided, explained, and signed by those who agreed to participate. Individuals who had very high blood pressure $(\geq 160 / 100 \mathrm{~mm} \mathrm{Hg})$ on the day of the test were excluded from the physical fitness tests. 
Each participant arrived at the center on a scheduled day and completed a data form. The first part of the form consisted of open and closed-ended questions. These dealt with identification information, existing diseases, current medications, amount of regular physical exercise per week, and results of clinical tests, including lipid profiles (high/low-density lipoprotein, total cholesterol, and triglycerides), and fasting blood glucose. To confirm the information provided by the participants, they were requested to bring the results of their most recent clinical examination.

\subsection{Anthropometric measurements}

The second part of the form was dedicated to blood pressure, weight, and height measurements, in addition to measurements of waist and hip circumferences. The evaluators (pre-trained teachers and trainees) used the Omron-HEM7113 automatic device to measure blood pressure and observed the procedure recommended in the VI Brazilian Hypertension Guidelines (SBC, 2010). For the measurement of each participant's weight, an electronic scale (Plenna brand, Sport model) that supported a weight of $150 \mathrm{~kg}$ was used. The participants were asked to be barefoot and to wear only shorts and a t-shirt. Each participant's weight was recorded in kilograms to one decimal place. The participant's stature was obtained using a portable stadiometer (Caprice Sanny), with the participant remaining barefoot. Waist and hip circumferences were measured using an anthropometric tape (WCS brand), according to the recommendation of the World Health Organization (WHO, 2008).

\subsection{Functional evaluations}

The third and final part of the protocol consisted of functional evaluations. For the verification of lower body strength (LBS) (30-sec chair stand), upper body strength (UBS) (30-sec arm curl), and posterior chain range of motion (PCROM) (seat-and-reach), the protocol proposed by Rikli and Jones (2013) was used. For the evaluation of the static unipedal stance (SUPS), an adapted version of the protocol employed by Springer et al. (2007) was used. 
Based on the data collection, potential risk factors for cardiovascular diseases were characterized. Lipid profiles were classified according to the $\mathrm{V}$ Brazilian Guideline for Dyslipidemias and Prevention of Atherosclerosis (2013). Fasting blood glucose values were categorized according to the Guidelines of Brazilian Diabetes Society (2015). The blood pressure values were analyzed in accordance with VI Brazilian Guidelines for Hypertension (SBC, 2010). The body mass index (BMI) and waist-to-hip ratio (WHR) were classified according to Brazilian Guidelines for Obesity 2009/2010 (2009).

Physical fitness (UBS, LBS, and PCROM) was classified according to the categories proposed by Rikli and Jones (2013). As SUPS did not have parameters of normality, data presented in the study by Springer et al. (2007) were used as a reference for the results of the present study. To classify the risk of developing cardiovascular diseases, the data obtained were computed using the procedure proposed by D'Agostino et al. (2008).

\subsection{Ethics}

The study protocol was approved in August2016(CAAE\#56131816.0.0000.5338) by the Research Ethics Committee of the Municipal Health Department of Porto Alegre.

\subsection{Statistical analysis}

The Kolmogorov-Smirnov test was used to assess the normality of the data distribution. Descriptive statistics were used to summarize the data. All the data were analyzed using the SPSS $23^{\circledR}$ platform.

\section{Results}

The study consisted of 592 individuals (males: $n=62,10.5 \%$; women: $n=530,89.5 \%)$. The mean age of the participants was 65.21 years $( \pm 10.3)$, and the majority of the participants were 67 years (Table 1 ). 


\begin{tabular}{l|c|c|c|c}
\hline \multirow{2}{*}{} & \multicolumn{2}{|c|}{$\begin{array}{c}\text { Adults (n=152) } \\
\mathbf{( 5 1 . 9 7 y o l d \pm 6 . 0 6 )}\end{array}$} & \multicolumn{2}{c}{$\begin{array}{c}\text { Elderly (n=434) } \\
\mathbf{6 0 9 . 8 5 y o l d} \pm 6.88)\end{array}$} \\
\cline { 2 - 5 } & $\begin{array}{c}\text { Men } \\
(n=12)\end{array}$ & $\begin{array}{c}\text { Women } \\
(\mathrm{n}=140)\end{array}$ & $\begin{array}{c}\text { Men } \\
(\mathrm{n}=50)\end{array}$ & $\begin{array}{c}\text { Women } \\
(\mathrm{n}=384)\end{array}$ \\
\hline Ararigboia Park & $7(51.29 \pm 4.19)$ & $91(51.93 \pm 6.1)$ & $34(71.5 \pm 6.73)$ & $257(70.14 \pm 7.15)$ \\
\hline Tamandaré Park & $1(59)$ & $6(56.33 \pm 1.75)$ & $1(71)$ & $35(70.91 \pm 7.32)$ \\
\hline $\begin{array}{l}\text { Edgar Graeff } \\
\text { Square }\end{array}$ & $2(56 \pm 4.24)$ & $22(52.36 \pm 5.08)$ & $5(72.2 \pm 5.67)$ & $51(66.37 \pm 5.18)$ \\
\hline CECOVE & 0 & $8(50.88 \pm 8.41)$ & $3(73.67 \pm 5.51)$ & $23(65.65 \pm 5.64)$ \\
\hline CEPRIMA & $2(50.5 \pm 0.71)$ & $13(49.62 \pm 7.8)$ & $7(70.86 \pm 6.57)$ & $18(70.11 \pm 6.44)$ \\
\hline
\end{tabular}

Source: prepared by the authors.

In the questionnaire form, $55 \%$ of the participants stated they did not have any known chronic diseases or physical limitations. The other $45 \%$ reported some type of chronic disease or physical limitation. Many diseases and physical limitations (approximately $n=630$ ) were reported. In the study population, approximately $29 \%$ reported hypertension, and approximately $20 \%, 13 \%, 12 \%$, and $10 \%$ reported the presence of osteoarticular diseases, diabetes mellitus, dyslipidemia hypothyroidism, and respiratory diseases, respectively. Around another $5 \%$ reported various other diseases.

Regarding drugs frequently used, the answers varied greatly, with $77 \%$ $(n=455)$ of the participants reporting using some type of medication. There were more than 500 drugs mentioned. Many of these had the same active ingredients but had different trade names. The drugs were grouped by action class, and only drugs mentioned more than five times were taken into account. The drugs most frequently used were antihypertensive agents (44\%), statins $(17 \%)$, levothyroxine $(11 \%)$, osteoarticular drugs $(11 \%)$, antidiabetic drugs $(7 \%)$, proton pump inhibitors $(7 \%)$, and antidepressants (3\%).

Almost half the participants (48\%) reported engaging in some form of exercise. Although many types of physical exercises were mentioned, walking was the most common, mentioned by $59 \%$ of the participants, followed by aquatic activities (15\%), dance (14\%), and pilates $(12 \%)$. In general, the participants engaged in these activities twice a week, with $60 \mathrm{~min}$ in each session.

Approximately $65 \%$ of the participants provided the results of their clinical exams. The mean values were as follows: triglycerides, $123.70 \mathrm{mg} / \mathrm{dL}( \pm 80.88)$; 
HDL cholesterol, $58.64 \mathrm{mg} / \mathrm{dL}$ ( \pm 19.67$) ;$ LDL cholesterol, $118.80 \mathrm{mg} / \mathrm{dL}( \pm 37.47)$; total cholesterol, $192.86 \mathrm{mg} / \mathrm{dL}$ ( \pm 45.2$)$; and fasting blood glucose, $98.08 \mathrm{mg} / \mathrm{dL}$ $( \pm 22.08)$. In the majority of cases, the clinical data were satisfactory, although HDL cholesterol levels were lower than optimum in most participants. Results of the clinical examinations and classifications of the participants are shown in Table 2.

According to the blood pressure measurements, the systolic blood pressure of $44.8 \%$ of the participants was normal levels, and diastolic blood pressure was normal in $83.1 \%$ of cases. The results of all the participants are presented in Table 2.

Table 2 - Classification of lipids, fasting blood glucose, systolic and diastolic BP, BMl, waist circumference, and WHR.

\begin{tabular}{|c|c|c|}
\hline Variable & Classification & $\mathrm{n}(\%)$ \\
\hline \multirow{4}{*}{$\begin{array}{l}\text { Triglycerides } \\
(\mathrm{n}=387)\end{array}$} & Optimal & $285(73.6 \%)$ \\
\hline & Borderline high & $62(16 \%)$ \\
\hline & High & 39 (10.1\%) \\
\hline & Very high & $1(0.3 \%)$ \\
\hline \multirow{3}{*}{ Total cholesterol $(n=385)$} & Desirable & $214(55.6 \%)$ \\
\hline & Borderline high & $126(32.7 \%)$ \\
\hline & High & $45(11.7 \%)$ \\
\hline \multirow{5}{*}{ LDL cholesterol $(n=171)$} & Optimal & $61(35.7 \%)$ \\
\hline & Near or above optimal & $41(24 \%)$ \\
\hline & Borderline high & $49(28.7 \%)$ \\
\hline & High & $15(8.8 \%)$ \\
\hline & Very high & $5(2.9 \%)$ \\
\hline \multirow{2}{*}{$\begin{array}{l}\text { HDL cholesterol } \\
(n=374)\end{array}$} & High & $154(41.2 \%)$ \\
\hline & Low & $220(58.8 \%)$ \\
\hline \multirow{3}{*}{$\begin{array}{l}\text { Fasting blood glucose } \\
(n=360)\end{array}$} & Normal & $255(70.8 \%)$ \\
\hline & Impaired fasting glucose & $80(22.2 \%)$ \\
\hline & Diabetes & 25 (6.9\%) \\
\hline \multirow{6}{*}{$\begin{array}{l}\text { Systolic BP } \\
(n=585)\end{array}$} & Optimal & $143(24.4 \%)$ \\
\hline & Normal & 119 (20.3\%) \\
\hline & High-normal & $128(21.9 \%)$ \\
\hline & Hypertension I & $131(22.4 \%)$ \\
\hline & Hypertension II & $45(7.7 \%)$ \\
\hline & Hypertension III & $19(3.2 \%)$ \\
\hline
\end{tabular}


continuação

\begin{tabular}{|c|c|c|}
\hline Variable & Classification & $\mathrm{n}(\%)$ \\
\hline \multirow{6}{*}{ Diastolic BP $(n=585)$} & Optimal & $397(67.9 \%)$ \\
\hline & Normal & 89 (15.2\%) \\
\hline & High-normal & $36(6.2 \%)$ \\
\hline & Hypertension I & $45(7.7 \%)$ \\
\hline & Hypertension II & $13(2.2 \%)$ \\
\hline & Hypertension III & $5(0.9 \%)$ \\
\hline \multirow{6}{*}{ BMI $(n=580)$} & Low risk & $8(1.4 \%)$ \\
\hline & Normal & $204(35.2 \%)$ \\
\hline & Increased riek & $250(43.1 \%)$ \\
\hline & Moderate risk & $86(14.8 \%)$ \\
\hline & Severe risk & $29(5 \%)$ \\
\hline & Very severe risk & $3(0.5 \%)$ \\
\hline \multirow{3}{*}{$\begin{array}{l}\text { Waist Circumference } \\
(\mathrm{n}=583)\end{array}$} & Low risk & 174 (29.8\%) \\
\hline & Increased risk & $180(30.9 \%)$ \\
\hline & Substantially increased risk & 229 (39.3\%) \\
\hline \multirow{2}{*}{ WHR $(n=583)$} & Low risk & $269(46.1 \%)$ \\
\hline & Increased risk & $314(53.9 \%)$ \\
\hline
\end{tabular}

Source: prepared by the authors.

According to anthropometric measurements, the average values for waist circumference and hip circumference were $88.43 \mathrm{~cm}( \pm 11.30)$ and $102.15 \mathrm{~cm}$ ( \pm 8.97$)$, respectively. With regard to stature, the average value was $1.58 \mathrm{~m}( \pm 0.07)$, and the average BMI was $67.59 \mathrm{~kg}( \pm 12.46)$. The mean BMI of the participants was $26.75 \mathrm{~kg} / \mathrm{m}^{2}( \pm 4.25)$, and the mean WHR was $0.86( \pm 0.078)$. The data on each participant were categorized, and the results are presented in Table 2.

The mean values for the functional evaluations were as follows: UBS $=16.17$ ( \pm 4.21$)$, elbow flexion with the dominant segment; LBS $=13.17( \pm 6.83)$, complete movement full stands from a chair; and PCROM $=1.19 \mathrm{~cm}( \pm 8.41)$, with the dominant leg. The SUPS measurements were performed four times, and the average results of all the participants were recorded. For eyes open and left foot on the ground, the average value was $37.24^{\prime}( \pm 23.63)$. For eyes open and right foot on the ground, the average value was 38.46' ( \pm 22.91$)$. For eyes closed and left foot on the ground and eyes closed and right foot on the ground, the average values were $8.5^{\prime}( \pm 10.47)$ and $8.43^{\prime}( \pm 10.28)$, respectively.

As with the previous measurements, the functional evaluations were categorized according to the performance of each participant. The results are presented in Tables 3 and 4. 
Table 3 - Strength and range of motion prevalence.

\begin{tabular}{l|c|c|c}
\hline & UBS $(\mathbf{n}=\mathbf{4 9 9})$ & LBS $(\mathbf{n = 4 8 9})$ & PCROM $(\mathbf{n = 4 9 8 )}$ \\
\hline No reference & 127 & 127 & 126 \\
\hline Below expected & $40(10.2 \%)$ & $92(25.4 \%)$ & $81(21.8 \%)$ \\
\hline Expected & $229(61.6 \%)$ & $212(58.6 \%)$ & $164(44.1 \%)$ \\
\hline Above expected & $103(27.7 \%)$ & $58(16 \%)$ & $127(34.1 \%)$ \\
\hline
\end{tabular}

Source: prepared by the authors.

Table 4 - Static unipedal stance test prevalence.

\begin{tabular}{l|c|c|c|c}
\hline & \multicolumn{2}{|c|}{ Eyes opened (n=505) } & \multicolumn{2}{c}{ Eyes closed (n=505) } \\
\hline & $\begin{array}{c}\text { Left foot on the } \\
\text { floor }\end{array}$ & $\begin{array}{c}\text { Right foot on the } \\
\text { floor }\end{array}$ & $\begin{array}{c}\text { Left foot on the } \\
\text { floor }\end{array}$ & $\begin{array}{c}\text { Right foot on the } \\
\text { floor }\end{array}$ \\
\hline $\begin{array}{l}\text { Below } \\
\text { normative }\end{array}$ & $166(32.9 \%)$ & $142(28.1 \%)$ & $122(24.1 \%)$ & $116(23 \%)$ \\
\hline $\begin{array}{l}\text { Above } \\
\text { normative }\end{array}$ & $339(67.1 \%)$ & $363(71.9 \%)$ & $384(75.9 \%)$ & $359(77 \%)$ \\
\hline
\end{tabular}

Source: prepared by the authors.

The functional evaluations used in the present study were designed to be applied to an elderly population. In this study, the population also included adults $(n=127)$. Due to a lack of data, human resources, and time, the same evaluations were applied to this population. This is the reason for the existence of "no reference" results in Table 3. As shown by the results of the analysis, $64 \%$ of the participants did not reach the minimum reference values for individuals aged 60-64 years in the UBS evaluation, $75 \%$ did not reach the minimum values in the LBS evaluation, and $16 \%$ did not reach the minimum values in the PCROM test.

To determine the likelihood of a participant developing cardiovascular disease in the next 10 years, the Framingham score was calculated using data on the sex and age of participants and the presence or absence of diabetes, HDL levels, total cholesterol levels, and systolic blood pressure. Most of the men $(58.6 \%)$ had a score of $10-14 \%$, and most of the women (39.5\%) had a score of $15-19 \%$. The results of the evaluation are presented in Table 5. 
Table 5 - Cardiovascular risk by the Framingham Score.

\begin{tabular}{l|c|c}
\hline Risk & Men $(\mathbf{n}=\mathbf{2 9})$ & Women $(\mathbf{n}=\mathbf{3 0 2})$ \\
\hline $\mathbf{0 - 4} \%$ & $1(3.4 \%)$ & $6(2 \%)$ \\
\hline $\mathbf{5 - 9} \%$ & $1(3.4 \%)$ & $24(7.9 \%)$ \\
\hline $\mathbf{1 0 - 1 4 \%}$ & $17(58.6 \%)$ & $106(35.1 \%)$ \\
\hline $\mathbf{1 5 - 1 9 \%}$ & $10(34.3 \%)$ & $119(39.5 \%)$ \\
\hline $\mathbf{2 0} \%$ & 0 & $47(15.5 \%)$ \\
\hline
\end{tabular}

Source: prepared by the authors.

4 Discussion

Some findings of the present study are a cause for concern. These include the prevalence of the use of proton pump inhibitors, without proper prescription. Furthermore, a large proportion of the participants cannot be classified as physically active, despite participating in a physical exercise program. The body mass distribution of the participants, as well as the prevalence of high systolic and diastolic pressure, inadequate total cholesterol, LDL, HDL, and prediabetes, pointed to a risk for associated comorbidities. As shown by the results of the physical fitness tests, the abilities of the elderly participants exceeded the expected levels for this age group.

Regarding self-reported diseases and commonly used medications, the characteristics of the participants in the present study resemble those of the population studied by Sardinha et al.(2015). The participants also appeared to be able to associate their illnesses with the medications they used. Six drugs were commonly mentioned in conjunction with the five most prevalent diseases. Sardinha et al. (2015) reported similar results, finding that individuals with a specific disease, in general, made use of the most appropriate medicine and knew how to make this discernment.

As noted above, a striking finding of the present study was the frequent use of proton pump inhibitors (e.g., esomeprazole, omeprazole, and pantoprazole). Among the indications for this class of medications are gastroesophageal reflux, peptic ulcers, ulcers induced by continued use of nonsteroidal anti-inflammatory drugs, Helicobacter pylori infection, and other hypersecretion syndromes. The use of this class of drugs in an uncontrolled manner can be harmful. If taken for prolonged periods, it can result in the development of pneumonia, hip fractures, malabsorption of nutrients, and other diseases (AKRAM et al., 2014). In the present study, gastritis, gastroesophageal reflux, and esophagitis diseases were mentioned only four times. On the other hand, the use of nonsteroidal anti-inflammatory drugs was mentioned by more than 40 of the participants. The use of proton bomb inhibitors may be largely 
associated with the prevention of ulcers caused by the continued use of nonsteroidal drugs, as there were few references to the direct treatment of any disease.

This study sample has a bias regarding the practice of physical exercise. Everyone, a priori, engaged in moderate to intense physical exercise, as they undertook exercise at least twice a week (60 min each session). According to the IPAQ classification, they would be placed in the Irregularly Active B category. In addition, $48 \%$ of the participants reported that they engaged in other systematic exercise (twice a week, $60 \mathrm{~min} / \mathrm{session}$ ). Based on the IPAQ classification, they would be placed as Active. Such findings are below what Barbosa et al. (2015) found among elderly people in urban areas. This sample bias turns out to be a fallacy, as most of the study participants (52\%) cannot be considered active. Thus, they do not gain all the benefits provided by physical exercise.

Among the participants in the present study, approximately 33\% were hypertensive. Picon et al. (2012) presented similar results in a meta-analysis, in which they reported a $6 \%$ decrease in the prevalence of hypertension in the last 30 years. Despite warning signs and drug treatment, the prevalence of hypertension among adults in Brazil remains high (30\%), which demonstrates the need for more effective action in the field of health promotion.

Regarding the body mass distribution measurements (waist circumference and BMI), most of the participants in the present study could be classified as having an increased cardiovascular risk. The risk found in the present study was lower than that reported by Howel (2012) in a study of English elders aged $70-89$ years. In the present study, among the individuals aged 70 years or older $(n=195)$, a similar risk was found, pointing to some risk due to the increase in waist circumference among approximately $70 \%$ of the participants. Among men, this number decreased to $43 \%$, and among women it rose to $75 \%$. In a study conducted in Germany of adults aged 45-64 years over a 10-year period, Haftenberger et al. (2016) reported that the waist circumferences of men and women increased by $0.53 \mathrm{~cm} /$ year and $0.63 \mathrm{~cm} /$ year, respectively. Based on the waist circumference data in the present study, the number of participants with a low cardiovascular risk was similar to that reported in the studies included in the German meta-analysis. The tendency for waist circumference to increase with aging may result in the participants in the present study having a higher cardiovascular risk in the future if no preventive action is taken.

The mean values of triglycerides and cholesterol (HDL, LDL, and total) found in the present study were quite similar to those reported by Carrol et al. (2012) in a U.S. population. In their study, they observed a trend of lowering lipid levels among those aged older than 20 years between 1988 and 2010. This decrease was accompanied by the increased use of specific drugs. In the present study, 
the cholesterol levels of most of the participants adhered to target values, and a significant number of the participants were taking statins.

When the results of fasting blood glucose levels were analyzed, they were in agreement with those observed previously in a Brazilian population. According to the Ministry of Health (BRASIL, 2015), 6.2\% of Brazilians have diabetes, and the prevalence of diabetes is age dependent. In the present study, the figure was $6.9 \%$, and the prevalence of the disorder was greater among older individuals. However, the findings of the present study are different from those found in a U.S. study (Caspersen et al., 2015), where the prevalence of diabetes and prediabetes among the population aged over 50 years varied between $56.5 \%$ and $79.1 \%$, depending on the age group and sex. In the present study, the prevalence of prediabetes and diabetes was approximately $29 \%$. In the U.S. study, the authors reported a trend of increasing numbers of diabetics with aging. The same was observed in the present study when the results were grouped using the same age ranges as employed in the U.S. study (50-64 years, $65-74$ years, and +75 years). The number of diabetics and prediabetics increased in these age groups by $22.8 \%, 29.9 \%$, and $40.1 \%$, respectively.

Acquired diabetes is dependent on lifestyle factors, including eating habits. This may be one of the differences between Brazilian and American samples. Although the number of diabetics in the present study was small, new strategies to control the disorder need to be put in place to improve the quality of life of individuals with diabetes and their prognosis.

The strength and PCROM of the elderly in the present study were both very satisfactory. Participants achieved "expected" or "above expected" results in approximately $89 \%$ of the UBS tests, $75 \%$ of the LBS tests, and $78 \%$ of the PCROM tests. In terms of the literature, the findings of the present study are very similar to those found in a study carried out in the city of Curitiba, Brazil (VAGETTI et al., 2015), in which groups of elderly women participated in physical exercise programs organized by the public service network. To better understand similarities and differences between the groups, more information is needed on the types of activities offered by both municipalities, as well as the characteristics of the participants. With regard to the LBS assessment, the data from the present study are similar to data in a study by Hansen et al. (2013) of a Finnish population. In the Finnish study, as well as the Curitiba study, the results revealed a tendency toward decreased performance in strength tests with advancing age. Likewise, in the present study, the mean of the results decreased with increasing age. These results should be investigated further in future studies. 
In the present study, static balance was measured using the unipedal stance test, with eyes opened and closed. The performance of the participants in the present study was much better than that reported in a study by Springer et al. (2007). In their study, the participants were patients and caregivers in rehabilitation, physical therapy, and occupational therapy clinics. Although the patients were healthy, the problems that led them to use these clinics may have adversely influenced their performance in the test. On the other hand, the results of a study by Hall et al. (2016) were quite similar to those found in the present study, as well as the level of physical activity. In both studies, the majority of the participants were characterized as Irregularly Active B, thus enabling a more reliable comparison. The performance of the participants in the balance test in the present study declined with advancing age, beginning with $60 \mathrm{~s}$ in the youngest age range (30-39 years) to $13 \mathrm{~s}$ in the oldest age range (80-90 years). Hall et al. (2016) reported a similar trend. Loss of balance is a consequence of many factors, ranging from sarcopenia to disturbances of the vestibular-visual system.

The Framingham scale in the present study showed that approximately $78 \%$ of the participants had a low risk of developing cardiovascular disease in the next 10 years, $17 \%$ had a medium risk, and $4 \%$ had a high risk. In the present study, more women than men had a high risk, according to the Framingham scale. This result is in agreement with that of other research, such as the study by Lyngbæka et al. (2013), who showed that women with a statistically significantly higher Framingham score than men. In the present study, the mean score among women $(14.96 \pm 4.3)$ was higher than men (13.58 $\pm 2.65)$, and this finding was statistically significant. Although mortality due to cardiovascular diseases is higher among men in Brazil (BRASIL, 2012), women seem to have a greater risk of developing these diseases. Prevention among women seems to be more effective.

\section{5 conclusion}

In summary, the focus of the present study was to determine the health status of elderly individuals who took part in regular physical exercise programs in a variety of SME-PMPA units. With this aim in mind, different health indicators were investigated, from diseases and their treatment to the ability to perform specific types of movements. In general, the health status of the participants in the present study who undertook regular physical exercise closely resembled that reported in similar populations. However, this is not to say that the results 
were satisfactory when the goal of physical exercise is to promote health. Based on the results of the following study, the following conclusions can be drawn.

First, with regard to diseases and drug treatment, individuals should be encouraged to take an active role in their own care. Although many of the participants were aware of which regular medications they took for chronic diseases, some were unable to discriminate which drug they used for a specific ailment. In addition, there appeared to be indiscriminate use of proton pump inhibitors. Their use and possible contraindications should be discussed with participants in physical exercise groups.

Second, the levels of weekly physical exercise among the participants in this study, to a large extent, fell short of optimal levels. It is important that each SME-PMPA unit advertise its activities widely, as well as the activities of other units and other institutions. The creation of a care network in the field of physical exercise is extremely important, as it can facilitate the access of many people to exercise programs. Due to a lack of awareness, such individuals may often not exercise at all or take less exercise than they should do.

Third, when looking at various factors that play a role in cardiovascular diseases (BMI, WHR, lipid profiles, and fasting blood glucose), the values found in the present study were similar to those reported in other research studies. This finding is cause for concern, as cardiovascular diseases are the main cause of death among the adult population. Although some mortality may be attributed to nonpreventable factors (e.g., birth defects), poor lifestyle habits can also play a role. The latter can be modified to improve the health status of the population. Investments in health promotion initiatives to encourage people to undertake regular physical exercise could help to reverse the global epidemic of cardiovascular disease, which is associated with high mortality and restricts active participation of many people in society.

Fourth, the performance in the execution of the strength, range of motion, and balance tests was satisfactory for elderly individuals (i.e., those older 60 years). However, the participants younger than 60 years performed poorly. In addition to increasing access to physical exercise for the elderly, it is also important to provide exercise modalities that are attractive to middle-aged people. At present, this population does not seem to avail of exercise programs, either because of a lack of time or because the available programs are unattractive to this age group.

Finally, men were under-represented in the SME-PMPA exercise groups and therefore do not represent the male population of the city. To improve their health status and reduce mortality in this population, strategies are needed to encourage males to take part in regular physical exercise programs. 
CONDIÇÕES DE SAÚDE, APTIDÃO FÍSICA

E RISCO ESTIMADO DE DOENÇAS

CARDIOVASCULARES EM UMA POPULAÇÃO

FISICAMENTE ATIVA DE PORTO ALEGRE -

BRASIL

resumo

Objetivos: O objetivo do presente estudo foi conhecer as condições de saúde e o risco cardiovascular estimado de uma população fisicamente ativa de Porto Alegre/RS. Metodologia: Compuseram a amostra 592 pessoas adultas e idosas de cinco unidades da SME-PMPA. O protocolo utilizado consistia de anamnese e avaliações antropométricas e funcionais. Resultados: Os resultados mostraram que existe compatibilidade entre as doenças autorreferidas e os medicamentos utilizados regularmente. Chama a atenção a grande referência ao uso dos inibidores de bombas de prótons. Os participantes podem ser classificados entre irregularmente ativos e ativos segundo classificação do IPAQ. A pressão arterial sistólica de 44,8\% e diastólica de 83,1\% foi classificada como ótima e normal. O perfil lipídico, com exceção do colesterol HDL, foi considerado satisfatório para a maioria. A classificação da glicemia em jejum, por sua vez, indicou a existência de 29\% de pré-diabéticos e diabéticos, este último com 6,9\%. A avaliação antropométrica (IMC e RCQ) mostrou que a maioria estava com risco aumentado ou superior. As avaliações funcionais (força, equilíbrio e amplitude de movimento) mostraram que a maioria dos idosos encontra-se em níveis satisfatórios ou acima deles. Os adultos, por outro lado, não apresentam os mesmos resultados nos testes de força. O escore de Framingham mostrou que $4 \%$ apresenta alto risco cardiovascular. Considerações finais: Esses resultados estão de acordo com as características da população, contudo, um grande número de pessoas apresenta indicadores de saúde inadequados, havendo necessidade de traçar novas estratégias para melhorá-los.

palavras-chave

Estilo de Vida. Exercício. Doenças Cardiovasculares. Educação para a Saúde. 
ABESO. Associação Brasileira para o Estudo da Obesidade e da Síndrome Metabólica. Diretrizes Brasileiras de Obesidade 2009/2010. 3. ed. Itapevi: AC Farmacêutica, 2009.

AKRAM, Faroog et al. Proton pump inhibitors: are we still prescribing them without valid indications? Australasian Medical Journal, v. 7, n. 11, p. 465-470, 2014.

AZAMBUJA, Maria Inês Reinert et al. Impacto econômico dos casos de doença cardiovascular grave no Brasil: uma estimativa baseada em dados secundários. Arquivos Brasileiros de Cardiologia, São Paulo, v. 91, n. 3, p. 163-171, set. 2008.

BARBOSA, Anderson Pedroso et al. Level of physical activity and quality of life: a comparative study among the elderly of rural and urban areas. Revista Brasileira de Geriatria e Gerontologia, Rio de Janeiro, v. 18, n. 4, p. 743-754, dez. 2015.

BRASIL. Ministério da Saúde. Datasus. Rede Integrada de Informações para a Saúde. Taxa de mortalidade especiffica por doenças do aparelho circulatório. 2012. Disponível em: <http://tabnet.datasus.gov.br/cgi/deftohtm.exe?idb2012/c08.deff>. Acesso em: 27 out. 2016.

- Ministério da Saúde. Portal Brasil. Diabetes atinge 9 milhões de brasileiros. 2015. Disponível em: <http://www.brasil.gov.br/saude/2015/07/diabetes-atinge-9milhoes-de-brasileiros>. Acesso em: 18 out. 2016.

- Ministério da Saúde. Portal Brasil. Doenças cardiovasculares causam quase 30\% das mortes no País. 2001. Disponível em: <http://www.brasil.gov.br/saude/2011/09/ doencas-cardiovasculares-causam-quase-30-das-mortes-no-pais>. Acesso em: 4 ago. 2016.

CARROL, Margaret D. et al. Trends in Lipids and Lipoproteins in US Adults, 1988-2010. Journal of the American Medical Association, v. 308, n. 15, p. 1545-1554, out. 2012.

CASPERSEN, Carl J. et al. Secular Changes in Prediabetes Indicators among Older-Adult Americans, 1999-2010. American Journal Preventive Medicine, Rockville, v. 48, n. 3, p. 253-263, jan./mar. 2015.

D'AGOSTINO, Ralph B. et al. General Cardiovascular Risk Profile for Use in Primary Care: the Framingham Heart Study. Circulation, Dallas, v. 117, n. 6, p. 743-753, fev. 2008.

FUNG, Teresa et al. Food quality score and the risk of coronary artery disease: a prospective analysis in 3 cohorts. American Journal of Clinical Nutrition, Rockville, v. 104 , n. 1, p. 65-72, jul. 2016

HAFTENBERGER, Marjolein et al. Changes in Waist Circumference among German Adults over Time: Compiling Results of Seven Prospective Cohort Studies. Obesity Facts, Basileia, v. 9, n. 5, p. 332-343, out. 2016.

HALL, Katherine S. et al. Physical Performance Across the Adult Life Span: Correlates With Age and Physical Activity. The Journal of Gerontology, Washington, v. 74, n. 4, p. 572-578, 2016.

HANSEN, Andreas et al. Muscle strength and physical activity are associated with self-rated health in an adult Danish population. Preventive Medicine, Amsterdam, v. 57, n. 6, p. 792-798, dez. 2013.

HOWL, Denise. Waist Circumference and Abdominal Obesity among Older Adults: Patterns, Prevalence and Trends. PLoS One, Rockville, v. 7, n. 10, e48528, 2012.

JAIN, Sharad. Effect of 6 weeks pranava yoga training on cardiovascular parameters in prehypertensive young adults. National Journal of Physiology, Pharmacy and Pharmacology, v. 6, n. 5, p. 1-4, 2016. 
LYNGB/EK, Stig et al. Cardiovascular risk prediction in the general population with use of suPAR, CRP, and Framingham Risk Score. International Journal of Cardiology, v. 167, n. 6, p. 2904-2911, 2013.

PICON, Rafael et al. Trends in Prevalence of Hypertension in Brazil: A Systematic Review with Meta-Analysis. PLoS One, Rockville, v. 7, n. 10, p. 112-123, 2012.

RIKLI, Roberta; JONES, C. Jesse. Senior Fitness Test Manual. 2. ed. Champaign: Human Kinetics, 2013.

SARDINHA, Ana Hélia de Lima et al. Adesão dos idosos com doenças crônicas ao tratamento medicamentoso. Revista de Pesquisa em Saúde, São Luís, v. 16, n. 3, p. 154-158, 2015

SOCIEDADE BRASILEIRA DE CARDIOLOGIA. Cardiômetro: Mortes por Doenças Cardiovasculares no Brasil, 2016. Dados dos anos anteriores. Disponível em: <http:// www.cardiometro.com.br/anteriores.asp>. Acesso em: 4 ago. 2016.

SOCIEDADE BRASILEIRA DE DIABETES. Diretrizes da Sociedade Brasileira de Diabetes: 2014-2015. São Paulo: AC Farmacêutica, 2015.

V Diretriz Brasileira de Dislipidemias e Prevenção da Aterosclerose. Arquivos Brasileiros de Cardiologia, São Paulo, v. 101, n. 4, supl. 1, p. 1-22, 2013.

Sociedade Brasileira de Hipertensão; Sociedade Brasileira de Nefrologia. VI Diretrizes Brasileiras de Hipertensão. Arquivos Brasileiros de Cardiologia, São Paulo, v. 95, n. 1, supl. 1, p. 1-51, 2010.

SPRINGER, Barbara et al. Normative Values for the Unipedal Stance Test with Eyes Open and Closed. Journal of Geriatric Physical Therapy, Rockville, v. 30, n. 1, p. 8-15, 2007.

VAGETTI, Gislaine Cristina et al. Functional fitness in older women from southern Brazil: normative scores and comparison with different countries. Revista Brasileira de Cineantropometria \& Desempenho Humano, Florianópolis, v. 17, n. 4, p. 472-484, jul./ago. 2015

WENZEL, Helmut; UNGER, Edgar. Influence of a six-month strengthening programme on HbA1c, cholesterol and triglycerides in type II diabetics: a pilot study (original research). South Eastern European Journal of Public Health, Lage, v. 5, p. 35-47, mar. 2016.

WORLD HEALTH ORGANIZATION. Waist circumference and waist-hip ratio: report of a WHO expert consultation. Geneva, 2008.

Data de submissão: 04/04/2017

Data de aprovação: 05/06/2017 
